restriction of the proposed interpretation to pressuremeter tests in which the sand is subjected to moderate values of strain. They have provided additional references for the reader, including their own comprehensive book (Baguelin, Jézéquel and Sheilds, 1978) which has recently been published, and which was not available when the Paper was prepared.

\title{
Estimating foundation settlements in sand from plate bearing tests
}

PARRY, R. H. G. (1978). Géotechnique 28, No. 1, 107-118.

\section{S. Thorburn, Thorburn and Partners, Consulting Civil and Structural Engineers, Foundation Engineering Consultants, Glasgow}

With the publication of the paper by Sutherland (1963) frequent reference has been made by UK researchers to the 1957 investigation by Gibbs and Holtz (1957) into the determination of the density of sands by means of the SPT.

It has been brought to the attention of the writer by several practitioners that the Gibbs and Holtz corrections to the recorded SPT results to allow for the effects of overburden pressure provide over-estimates of the relative densities of sand deposits. The lack of agreement between research and practice may be attributed to the laboratory conditions not being representative of field conditions (Thorburn, 1963).

Peck has concurred with this latter view and has stated that all relative densities estimated from $N$ values by the Gibbs and Holtz procedure are likely to be greater than the actual relative densities in the field. It would be of great assistance to researchers and practitioners if this twenty year old argument was resolved by proper research.

The conclusions of the British Geotechnical Society Sub-Committee on Penetration Testing (1974) is worthy of reference and the writer would be pleased to receive comments on this important debate from Mr Parry, particularly since he employs the Gibbs and Holtz correlations in his Paper.

\section{REFERENCES}

British Geotechnical Society (1974). Penetration testing in the United Kingdom. State-of-the-art report. Proc. Eur. Symp. on Penetration Testing, Stockholm 1.

Sutherland, H. B. (1963). The use of in situ tests to estimate the allowable bearing pressure of cohesionless soils. Struct. Engr. 41, 85-92.

Gibbs, H. J. \& Holtz, W. G. (1957). Research on determining the density of sands by spoon penetration testing. Proc. 4th Int. Conf. Soil Mech. Fdn Engng, London 1, 35-39.

Thorburn, S. (1963). Tentative correction chart for the standard penetration test in non-cohesive soils. Civ. Engng publ. Wks Rev. 58, No. 683, 752-753.

\section{A. Holmberg, Åke Holmberg, Lund, Sweden}

Forssell (1977) made the assumption that one part of the settlement under a loaded plate on sand, $a_{\mathrm{el}}$, was a function of the elasticity of the sand material. Another part, $a_{\phi}$ was a function of relative movements between the sand particles, caused by friction.

Thus

$$
a_{\mathrm{el}}=\sigma_{\mathrm{m}} \frac{\sqrt{A}}{K_{\mathrm{el}}}
$$

where $\sigma_{\mathrm{m}}=$ the mean bearing stress

$A=$ the bearing area

$K_{\mathrm{el}}=\mathrm{a}$ modulus depending on the shape of the bearing plate and on the elasticity of the sand material 
$a_{\phi}$ as in principle following from an angular deviation ought to be proportional to some distance, e.g. $\sqrt{ } A$. Under high loads this, however, holds also for the mean stresses under a loaded plate.

Thus

$$
a_{\phi}=\frac{\sigma_{\mathrm{m}}}{K_{\phi}}
$$

where $K_{\phi}=$ a modulus depending on the shape of the bearing plate and on the friction coefficient for the sand particles. As a result, under not too small loads,

$$
a=a_{\mathrm{el}}+a_{\phi}=\sigma_{\mathrm{m}}\left(\frac{\sqrt{A}}{K_{\mathrm{el}}}+\frac{1}{K_{\phi}}\right)
$$

giving in principle the same relation as that found by Kögler. Deviations are to be expected under small loads and under very high loads, when the sand is crushed under $\sigma>\sigma_{\mathrm{m}}$.

\section{REFERENCE}

Forssell, C. A. (1977). Lesson given 1934 in the Swedish Society of Engineers. Väg-o Vattenbygg., No. 4, Stockholm: Holmberg.

\section{E. Zolkov, Standards Institution of Israel}

The Author would have been well advised to adopt the old Hebrew maxim, 'Honour and suspect', when abstracting load test results which are to serve as the basis for a design method. Much of the data published refer to silty sands. Some even relate to organic sands. There seems to exist a general tendency for sands to become cleaner the further they are removed from their primary source in the technical literature. Furthermore quartz sands which do not necessarily behave similarly despite similar gradation and density, are very different to gypsum or carbonaceous sands.

The appropriateness of the exercises involved in deriving Fig. 5 is highly questionable. For example the inherent value in demonstrating the similarity of equation 2 of the paper (the well known Terzaghi and Peck formula) to a curve representing a highly hypothetical condition of relative density increasing progressively from $45 \%$ near the surface to $80 \%$ at $20 \mathrm{~m}$ depth, is dubious.

The importance of stress history has been neglected although it may be argued that the SPT $N$ expresses not only relative density at a particular depth, but also preloading effects and thus settlement computations based on a direct use of $N$ do take this factor into account.

On the basis of Gibbs and Holtz (1957) findings, the writer has found that $N$ at depth $D$ $\left(N_{\mathrm{D}}\right)$ may be related to $N$ at one meter depth $\left(N_{1}\right)$ to the overburden pressure $\sigma_{1}$, in uniformly dense sands to a depth of about 12 , in the medium to dense range by:

$$
N_{\mathrm{D}}=k N_{1} \sqrt{\sigma_{1}}
$$

where $k$ is between 0.7 and $1 \cdot 0$, depending on $D_{\mathrm{r}}$. There appears to be a growing body subscribing to the opinion that

$$
E=f \sqrt{\sigma}
$$

where $\sigma$ is the confining stress. These last two equations reinforce equation (4) of the Paper

$$
E \propto N
$$

The writer has had the opportunity to investigate the relative density distribution in a dune sand deposit. In this deposit there does not exist any overall density variation with depth. A typical distribution of $D_{\mathrm{r}}$ is shown in Fig. 1 which is for two vertical sections of the centre lines of a cubic block of sand of $1 \mathrm{~m}$ sides. 


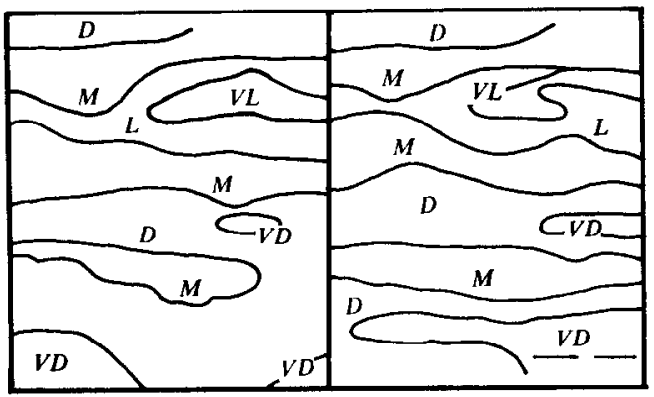

Fig. 1. Relative density pattern in $1 \mathrm{~m}$ cube

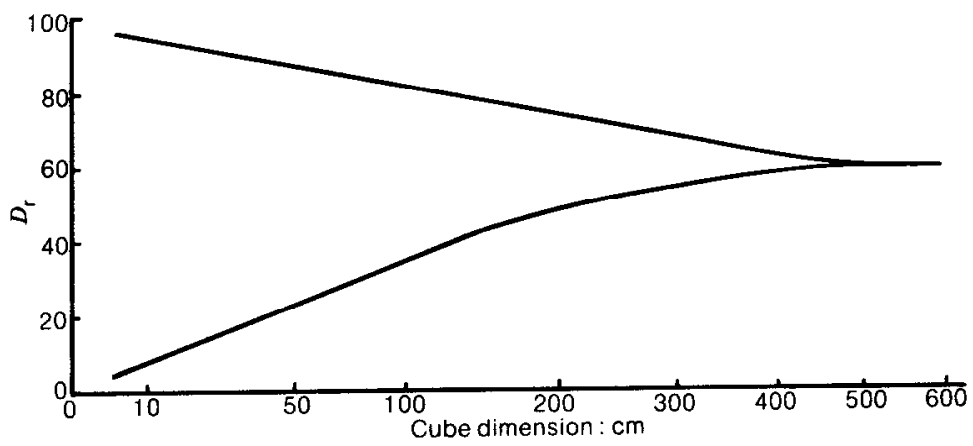

Fig. 2. $D_{\mathrm{r}}$ range against size of sample

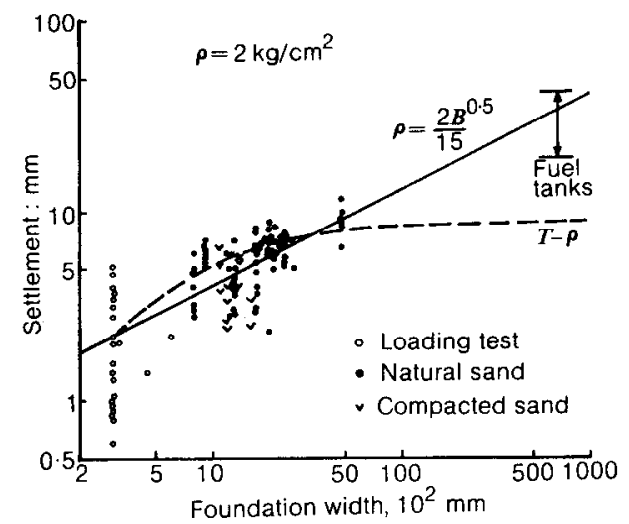

Fig. 3. Settlement against toundation width

Figure 2 shows the range of average relative densities existing as a function of the size of the sand volume considered. The smaller the soil volume considered, the larger is the range of average relative densities. This diagram explains much of the scatter appearing in Fig. 3 particularly for the small size plates or footings. The average relationship, between settlement $\rho(\mathrm{mm})$ and width or diameter $B(\mathrm{~mm})$ for a relative density of about $60 \%$ in this fine quartz dune sand deposit is

$$
\rho=\rho \frac{\sqrt{B}}{15}
$$

where $\rho$ is contact pressure in $\mathrm{kg} / \mathrm{cm}^{2}$. It is evident that the Terzaghi and Peck formula might 
underestimate settlements of large foundations. Of interest is the square root relationship found on a purely empirical basis. It should be recognized that the larger a foundation, the higher the confining stresses in the sand volume constituting the sea of settlement and therefore $E$ is in some manner related to $B$.

The data in Figs 2 and 3 should demonstrate the danger in extrapolating from one or a few small plate loading tests. The random variability of a sand deposit as a function of the size of the relevant soil volume must also be considered.

\section{REFERENCE}

Gibbs, H. J. \& Holtz, W. G. (1957). Research on determining the density of sands by spoon penetration testing.

Proc. Fourth Int. Conf. Soil Mech. Fdn Engng, London 1, 35-39.

\section{Author's reply}

In answer to Mr Thorburn, the carrying out of SPT in sand, in a tank could give higher $N$ values than in the field because of the confinement. Some account has been taken of this in recently suggested correction procedures (Peck, Hanson and Thorburn, 1974). It is, in fact, unnecessary to correct $N$ values at all in calculating settlements, except where stress changes occur subsequent to the site investigation, due for example to excavation or ground water level (Parry, 1971 and 1978b).

The Author (Parry, 1978a) has used the Gibbs and Holtz (1957) curves to convert assumed soil conditions into $N$ values, to allow settlement calculations to be made for various foundation widths relative to the settlement of a $0.3 \mathrm{~m}$ plate. As only relative settlements are calculated it is of no great importance if the Gibbs and Holtz curves do not express exactly the relationships between $N$ values on the one hand, and relative density and overburden pressure on the other. It is only necessary that the curves of $N$ against relative density for different overburden pressures should be reasonably correct relative to each other.

The Gibbs and Holtz type of correlation will be influenced not only by confinement, but also by soil type, as shown by Marcuson and Bieganousky (1977), but the relative positions of the curves remains consistent. The Gibbs and Holtz curves were used by the Author solely to illustrate that variations of soil density with depth must be taken into account in extrapolating settlements from plate tests to full scale foundations.

It is not necessary to use the Gibb and Holtz correlations, or any other similar correlations, to extrapolate from plate settlements. It is suggested in the Paper by the Author that, in addition to making the plate tests, other tests such as SPT, static cone or possibly pressuremeter, should be performed and these tests used directly to extrapolate from the plate settlements. An expression (equation 7) is given in the Paper by the Author for use with SPT results.

Mr Holmberg has given an interesting account of an early attempt to interpret the plate bearing test, but the method does not allow for different variations in soil conditions with depth.

Zolkov has the advantage over the Author in having access to the wisdom contained in the Hebrew maxims. Nevertheless the Author is aware that there are different types of sands and that not all sands are clean sands.

Clearly the Author cannot agree with Zolkov that the methods used to obtain Fig. 5 are highly questionable. The method was simply based on assuming certain soil conditions and then calculating relative settlements for different sizes of loaded areas. The aim was to show that widely different extrapolations were obtained even with these straight forward, but different, soil conditions. In no sense is Fig. 5 supposed to represent all possible soil conditions 
and it is not presented as a design chart. The design method recommended is based on equation 7, upon which Zolkov has made no comment.

That one of the extrapolations in Fig. 5 is very similar to the Terzaghi and Peck extrapolation is, of course, a coincidence, but does serve to show that such an extrapolation formula, which takes no account of soil conditions, can only apply, at best, to one particular soil condition.

Zolkov's own work, as described in his discussion, appears to be based on data fitting, an approach which does not necessarily demand a fundamental understanding of soil behaviour. It is encouraging, however, to note that the approach does appear to lend support to equation 4.

The random variability of density in sand which he describes clearly presents a problem in attempting to predict its behaviour. As in all problems of this type, however, there is much to be gained in starting from simple cases and extrapolating either mathematically or through the exercising of judgement, to the more complex cases, keeping in mind the need to remain faithful to basic principles. In conditions such as those described by Zolkov a simple expression such as equation 7 would have to be applied in a thoughtful, rather than routine, manner.

\section{REFERENCES}

Gibbs, H. J. \& Holtz, W. G. (1957). Research on determining the density of sands by spoon penetration testing. Proc. Fourth Int. Conf. Soil. Mech. Fdn Engng, London 1, 35-39.

Marcusun, W. F. \& Bieganousky, W. A. (1977). SPT and relative density in coarse sands. J. Geotech. Engng Div. Am. Soc. Civ. Engrs 103, GT11, 1295-1310.

Parry, R. H. G. (1971). A direct method of estimating settlements in sand from SPT values. Proc. Symp. on the Interaction of Structure and Foundation, Birmingham, 29-32.

Parry, R. H. G. (1978a). Estimating foundation settlements in sand from plate bearing tests. Géotechnique 28, No. 1, 107-118.

Parry, R. H. G. (1978b). Correspondence submitted to Ground Engineering.

Peck, R. B., Hanson, W. E. \& Thorburn, T. H. (1974). Foundation engineering. 2nd Edition. New York: John Wiley and Sons, 113-115. 